Article

\title{
Damping Assessment of Lightweight Timber Floors Under Human Walking Excitations
}

\author{
Alexander Opazo-Vega ${ }^{1,2, * \mathbb{C}}$, Francisco Muñoz-Valdebenito ${ }^{2}$ and Claudio Oyarzo-Vera ${ }^{2}$ (]) \\ 1 Department of Civil and Environmental Engineering, Universidad del Bío-Bío, Concepción 4081112, Chile \\ 2 Department of Civil Engineering, Universidad Católica de la Santísima Concepción, \\ Concepción 4090541, Chile \\ * Correspondence: aopazove@ubiobio.cl; Tel.: +56-41-311-1645
}

Received: 18 July 2019; Accepted: 4 September 2019; Published: 9 September 2019

\begin{abstract}
Vibrations on timber floors are among the most common serviceability problems in social housing projects. The presence of low damping levels on these floors could cause excessive vibrations in a range of frequency and amplitude that generate discomfort in users. This study focuses on the influence of the damping ratio in the dynamic serviceability of social housing timber floors due to walking excitations. More than 60 human-walking vibration tests were conducted on both laboratory and in-situ timber floors. The floors were instrumented with accelerometers, and fundamental modal damping ratios were estimated by applying Enhanced Frequency Decomposition Domain (EFDD) and Subspace Stochastic Identification (SSI) methods. The vibration dose value (VDV) was used to estimate the dynamic serviceability of floors. The results indicated that timber floors had an impulsive-type vibration response, with fundamental damping ratios between $1.9 \%$ and $14.8 \%$, depending on their constructive characteristics. The in-situ floors had damping ratios between two to three times greater than the laboratory floors due to the presence of non-structural elements. Finally, it was possible to demonstrate that the floors with the highest damping ratios reached lower vibration dose values and, therefore, a better dynamic serviceability performance.
\end{abstract}

Keywords: timber floor vibration; structural damping; operational modal analysis; dynamic serviceability

\section{Introduction}

Lightweight timber floors are attracting considerable interest in developing countries because of their advantages in terms of sustainability and construction speed. Among the different structural systems in buildings, floors are the only part with which human occupants are in constant physical contact. Therefore, this construction component could become a common source of complaints from the users, generated by the deflections and excessive vertical vibration of the floors while walking on them [1]. This issue, which is becoming more recurrent in diverse construction contexts, has generated a sustained increase in experimental research associated with the dynamic serviceability of timber floors [2].

Damping is one of the most influential factors in the human perception of transient vibration in a timber floor system [1]. This is because damping is an intrinsic property of structural systems that influences oscillation amplitudes and the rate of decay under forced and free vibrations, respectively [1]. Therefore, knowing the level of damping of a timber floor is an essential aspect for structural designers since vibrations tend to be more tolerable in floors that have higher damping [3].

On timber floors, damping comes from two primary sources: the material damping (due to the internal wood anatomy and its defects, such as knots and internal cracks) and structural damping (due to friction in the structural joints and friction between structural and non-structural elements) [3].Under human walking operational conditions, damping can be generated due to the combined effect of 
different small sources of non-linearity, such as joint friction, interaction between structural and non-structural elements, and the effect of the floor content. Hence, operational damping is not only generated by the intrinsic modal damping of the structure, but also because of all these other energy dissipation mechanisms. In terms of the structural performance, operational damping is more interesting to analyze than intrinsic modal damping, because this is the effect perceived by people.

From the above, it can be deduced that it is not realistic to define a single damping value that is representative of all timber floors. Therefore, each type of construction must be analyzed separately, since any difference in the construction technique or even in the workforce quality could generate different levels of damping [3].

Several studies have been published on damping ratio estimations for different kinds of timber floors constructed in laboratory-controlled conditions. Firstly, investigations focused on studying timber floors that allowed span lengths between $3 \mathrm{~m}$ and $5 \mathrm{~m}$ to be reached. The floors were generally built with glulam beams [3], an I-joist [4], and a metal web joist [5,6], nailed, screwed, or glued to particleboard or plywood flooring. The damping ratios obtained in these floors had values from $0.82 \%$ to $4.78 \%$ for the first resonant mode. Subsequently, research focused on studying timber floors that could reach greater span lengths, between $6 \mathrm{~m}$ and $8 \mathrm{~m}$. In this way, studies were carried out on timber floors built with laminated veneer lumber beams (LVL) [7], and cross-laminated timber (CLT)-concrete composite slabs [8]. Damping ratios between $0.52 \%$ and $1.29 \%$ for the first resonant mode were found for these floors. Most of the investigations mentioned above considered idealized support conditions for the floors and did not take into account the interaction with typical in-situ non-structural elements, such as ceilings on the floor's underside and partition walls.

On the other hand, in the last decade, only a few studies have focused on damping ratio estimations for in-situ timber floors. Initially, some researchers analyzed the damping ratios for traditional timber floors in the context of elementary schools [9] and multi-family buildings [10]. These floors generally had a main resistant structure composed of a series of engineered timber beams up to $12 \mathrm{~m}$ in length (I-joist, web-joist), oriented strand board (OSB) or plywood boards nailed or screwed on their upper edge to receive concrete topping, and gypsum boards at their bottom edge to increase fire resistance. The damping ratios obtained for the first resonant mode varied between $0.47 \%$ and $9.10 \%$. Subsequently, with the rise of industrialized construction, other researchers concentrated on studying the damping ratios of prefabricated timber floors for eight-story timber frame residential buildings [11] and five-story multi-family apartment buildings [12]. These floors generally had a main resistant structure composed of CLT slab panels and glulam beams, which often interacted with sophisticated ceiling systems and lightweight partition walls. The damping ratios obtained for the first resonant mode varied between $3.40 \%$ and $8.00 \%$.

Previous work has tended to focus on damping ratio estimations for high-quality timber floors that were constructed in developed countries. The aim of our work is to expand current knowledge on timber floors' damping to lightweight timber floors that are typical in Latin American social housing for low-income families. To the best of the authors' knowledge, no systematic investigation on the damping mechanisms that are activated under human-walking operational conditions has been previously presented in a timber floor context, where softwood species, low-depth timber joists, and unskilled labor are usually used. Such an investigation is presented herein. Generally, this kind of timber floor has a poor vibration performance, which is reflected in the adverse results of satisfaction surveys distributed to users by government institutions. In this context, we focused on the experimental estimation of damping ratios in both laboratory and in-situ timber floors. Different floor spans, support details, types of non-structural elements, and human walking conditions were considered. All the floors were instrumented with accelerometers, and subsequently, operational modal analysis techniques were applied. Finally, some conclusions about the influence of damping ratio levels on the floor vibration performance were made. With the experimental results of this research, it is hoped that this study can contribute to the future calibration of simplified formulas for the vibratory design of these low-cost timber floors, which correlate more complex parameters 
(frequencies, damping, vibration dose value) with simpler ones (vertical displacements, velocities, or accelerations due to point loads).

\section{Materials and Methods}

In Chile, timber social housing has substantial budget restrictions. Generally, these are two-storey single-family houses with a total area of up to 60 square meters. The floor systems are characterized by $41 \mathrm{~mm} \times 138 \mathrm{~mm} \mathrm{C} 24$ [13] radiata pine joists, spaced $410 \mathrm{~mm}$ at the center, with span lengths between $2.1 \mathrm{~m}$ and $3.1 \mathrm{~m}$. Usually, the joists are laterally restrained by $41 \mathrm{~mm} \times 138 \mathrm{~mm}$ radiata pine elements (hereafter "blocking"), spaced between $410 \mathrm{~mm}$ and $1220 \mathrm{~mm}$. The deck is formed with $15 \mathrm{~mm}$ thick plywood boards, and the ceiling consists of $10 \mathrm{~mm}$ thick gypsum boards. The ceiling support consists of $41 \mathrm{~mm} \times 41 \mathrm{~mm}$ radiata pine battens spaced at $400 \mathrm{~mm}$, which in turn are connected to the timber joists. All the connections between components are nailed or screwed and spaced up to $300 \mathrm{~mm}$ at the center. The main nominal properties of these components [13] and their construction details are shown in Table 1 and Figure 1, respectively.

Table 1. Nominal density and Young's modulus (E) of timber floor components.

\begin{tabular}{cccc}
\hline Component & Density ${ }^{\mathbf{1}} \mathbf{( \mathbf { k g } / \mathbf { m } ^ { \mathbf { 3 } } )}$ & E Parallel (MPa) & E Perpendicular (MPa) \\
\hline Timber joist & 476 & 9545 & 621 \\
Timber blocking & 476 & 9545 & 621 \\
Timber battens & 476 & 7900 & 514 \\
Plywood board & 538 & 6921 & 2353 \\
Gypsum board & 750 & $\mathrm{n} / \mathrm{a}$ & $\mathrm{n} / \mathrm{a}$ \\
\hline \multicolumn{5}{c}{}
\end{tabular}

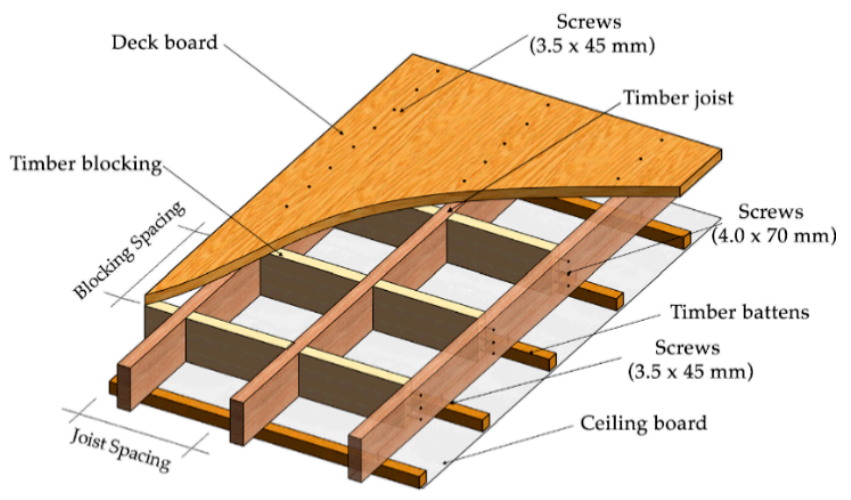

Figure 1. Typical construction details of timber floors in Chilean social housing.

The experimental plan of this work was divided into two stages. In the first stage, timber floors built in a laboratory under well-controlled conditions were studied, for analyzing different span lengths and support connections. Then, a second stage focused on studying in-situ floors was carried out, to consider real support conditions and the effect of non-structural components.

\subsection{Laboratory Tests}

Eight timber floors with four different span lengths ( $3 \mathrm{~m}, 2.7 \mathrm{~m}, 2.4 \mathrm{~m}$, and $2.1 \mathrm{~m})$, and two kinds of wall-to-joist connections (wood-based and steel-based), were built in laboratory-controlled conditions. The span lengths were selected in order to represent the typical ranges present in social housing and to study the effect of the vibration amplitude on the floor damping ratios. Meanwhile, the two types of wall-to-joist connections were chosen for analyzing the influence of different energy dissipation conditions due to support friction on the floor's vibration performance. All the floors were simply-supported on four sides, and none of them had additional non-structural elements, such as 
partition walls or ceiling sheathings. Temperature and relative humidity were not explicitly controlled, but were according to standard indoor spring seasonal conditions, i.e., $18{ }^{\circ} \mathrm{C}$ and $65 \%$, respectively. Figures 2 and 3 and Table 2 show the construction details of the laboratory floors tested.

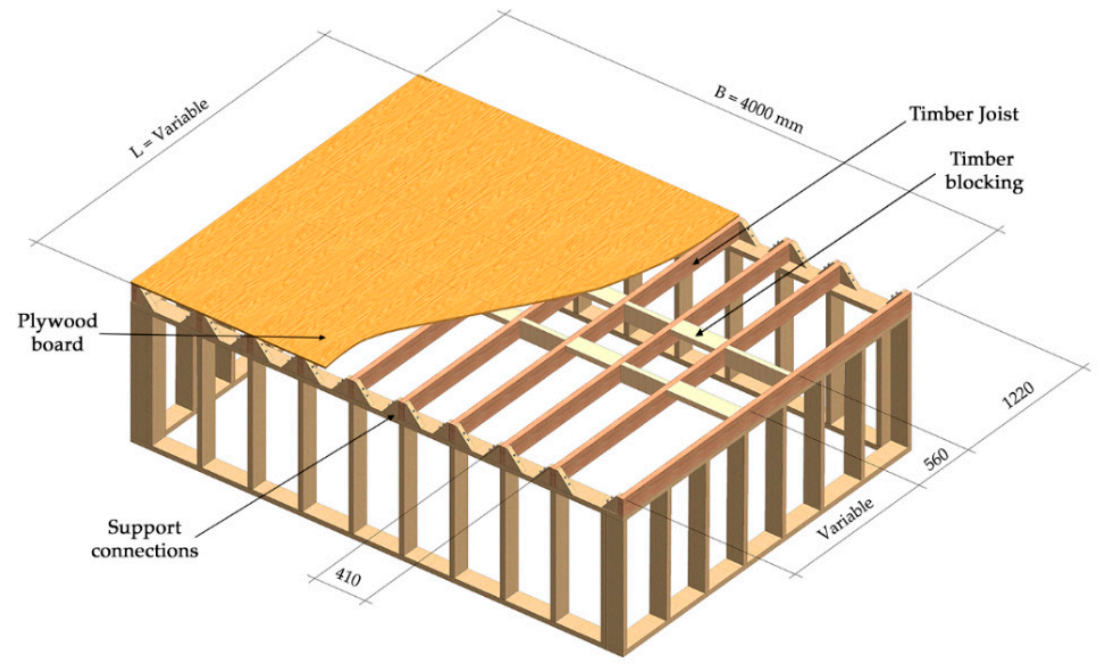

Figure 2. Layout and dimensions of a typical laboratory test specimen.

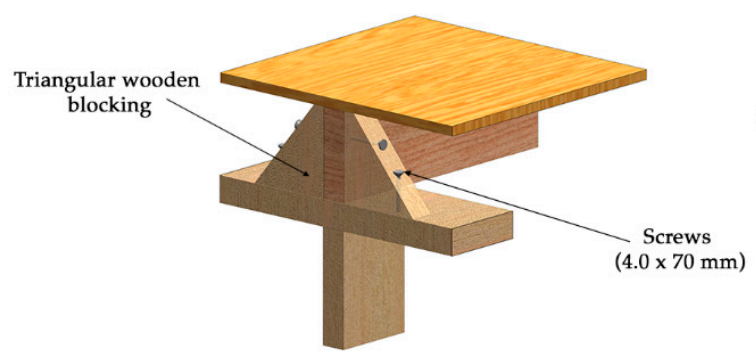

(a)

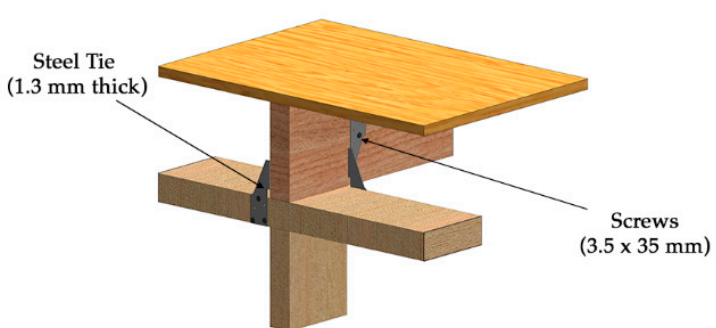

(b)

Figure 3. (a) Wood-based wall-to-joist connections; (b) steel-based wall-to-joist connections.

Table 2. Nomenclature, dimensions, and support details of laboratory timber floors.

\begin{tabular}{cccc}
\hline Series & Span Length “L” $(\mathbf{m})$ & Floor Width “B” $(\mathbf{m})$ & Support Type \\
\hline Lab-2.1-W & 2.1 & 4.0 & Wood-based \\
Lab-2.1-S & 2.1 & 4.0 & Steel-based \\
Lab-2.4-W & 2.4 & 4.0 & Wood-based \\
Lab-2.4-S & 2.4 & 4.0 & Steel-based \\
Lab-2.7-W & 2.7 & 4.0 & Wood-based \\
Lab-2.7-S & 2.7 & 4.0 & Steel-based \\
Lab-3.0-W & 3.0 & 4.0 & Wood-based \\
Lab-3.0-S & 3.0 & 4.0 & Steel-based \\
\hline
\end{tabular}

As a vibration source, a set of 36 short-duration walks were performed on each floor considering the different body masses of the walkers (between $56 \mathrm{~kg}$ and $87 \mathrm{~kg}$ ) and step frequencies (between $1.4 \mathrm{~Hz}$ and $2.2 \mathrm{~Hz}$ ). A portable metronome helped to synchronize the step frequencies and to generate a more representative set of walks. Vertical accelerations were recorded for the walking tests through five uniaxial accelerometers screwed to the top surface of the floors. The sensors were evenly spaced and located at the center lines of the timber floors (i.e., $1 / 4$ th, 2/4th, and 3/4th of both span length and floor width). Integrated circuit piezoelectric (ICP) accelerometers (model 603C01) were used, having 
a sensitivity of $100 \mathrm{mV} / \mathrm{g}$. Accelerometer data acquisition was conducted through a multi-channel dynamic signal acquisition module (model NI 9234) gathered into a Compact DAQ chassis (model cDAQ-9174) and linked via USB to a laptop. For all tests, the sampling rate was set to $1652 \mathrm{~Hz}$. The typical walking paths, accelerometer locations, and instrumentation setup are shown in Figure 4.

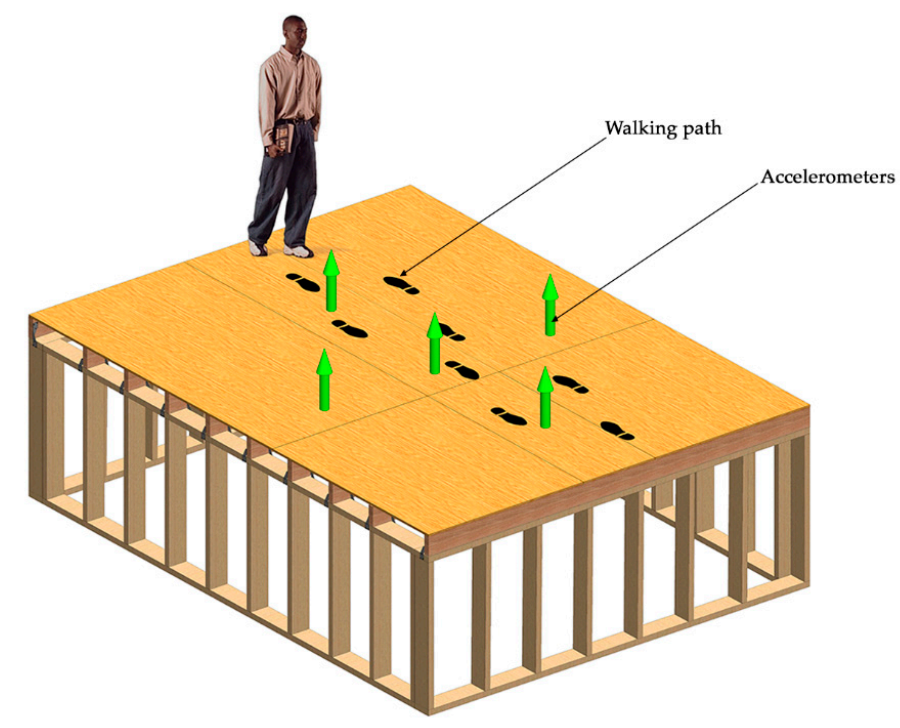

(a)

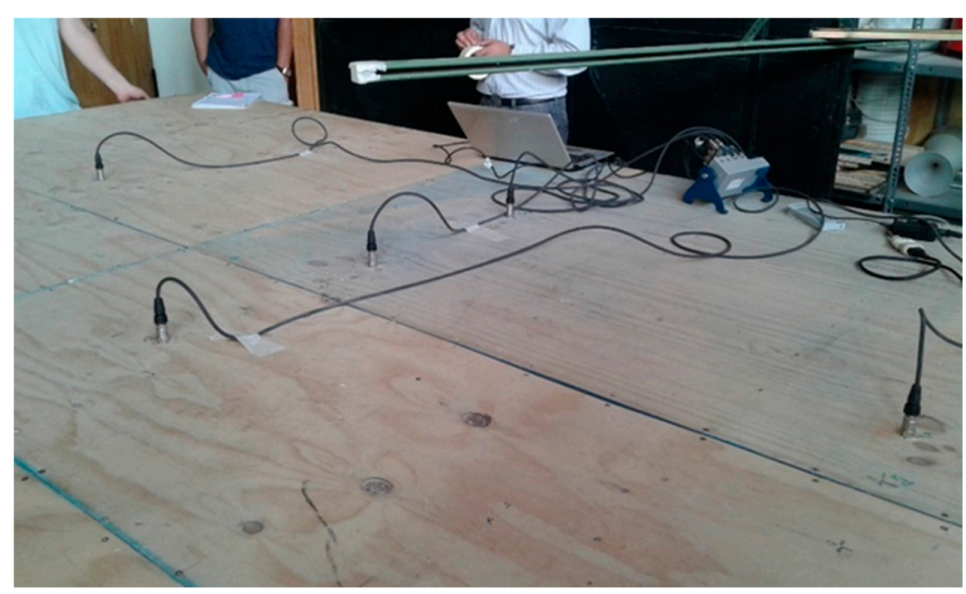

(b)

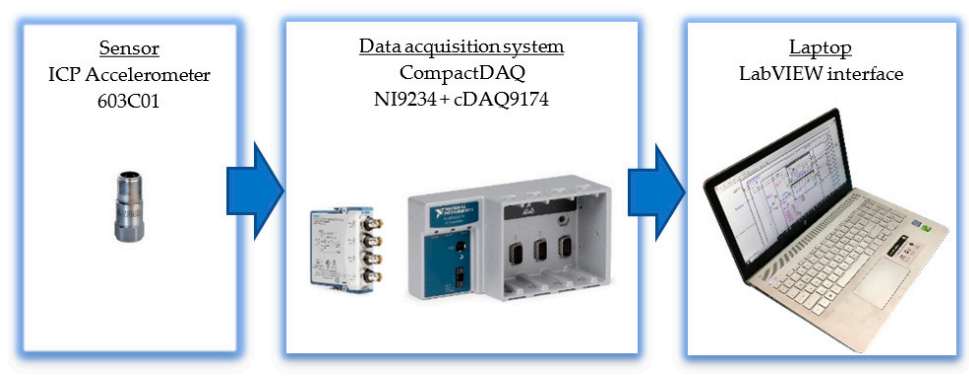

(c)

Figure 4. (a) Walking paths and accelerometer locations, (b) test setup on laboratory timber floors, and (c) instrumentation diagram.

In general, this study was looking for a methodology that would also allow field evaluations with a minimum number of sensors and the time for installing sensors and recording data to be 
optimized, especially in the case of in-situ tests performed in houses occupied by families. In all cases, we selected measuring points avoiding modal nodes to capture the highest possible number of vibration modes. Having all the above in mind, we used the recommendations given by [14] in order to perform successful operational modal testing and analysis.

\subsection{In-Situ Tests}

In this stage, timber floors of two kinds of houses were studied. All the floors were wood-based, supported on their four sides, and had some partition walls on their upper face and a ceiling on their lower face. One timber floor had a maximum span length of $2.4 \mathrm{~m}$ (henceforth named Field-2.4-W), and the other $3.1 \mathrm{~m}$ (hereafter Field-3.1-W). Figures 5 and 6 and Table 3 present the construction details of the in-situ timber floors tested. The vibration source, accelerometer models, and signal acquisition details were similar to those used on the laboratory timber floors. However, due to space restrictions in the houses, only four accelerometers were used, which were evenly spaced and located along a line that passed through the center of the joists (Figure 7).

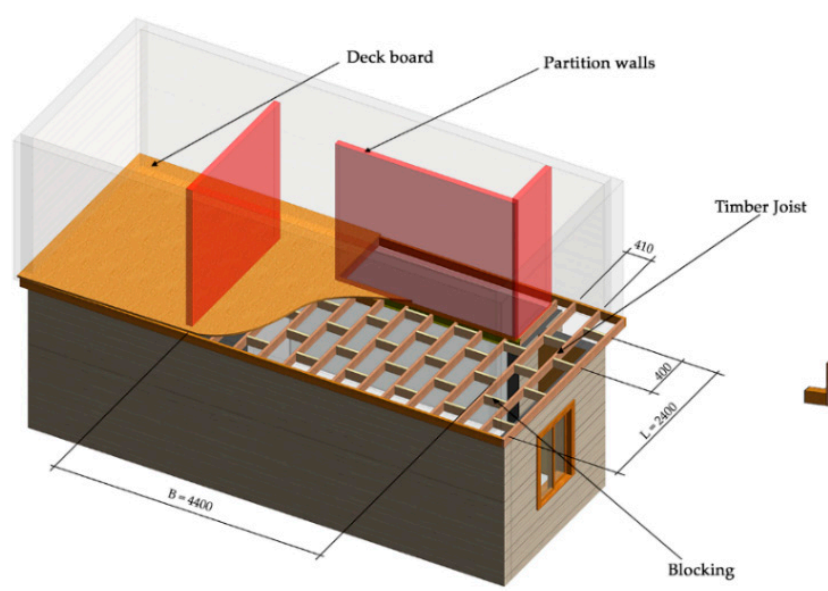

(a)

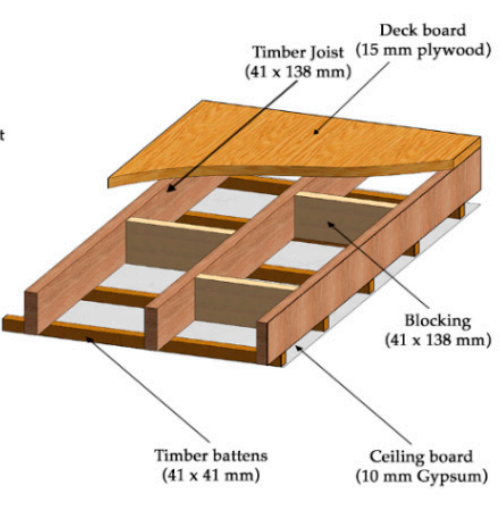

(b)

Figure 5. (a) Layout and dimensions of the Field-2.4-W timber floor.; (b) ceiling-to-joist connections of the Field-2.4-W timber floor.

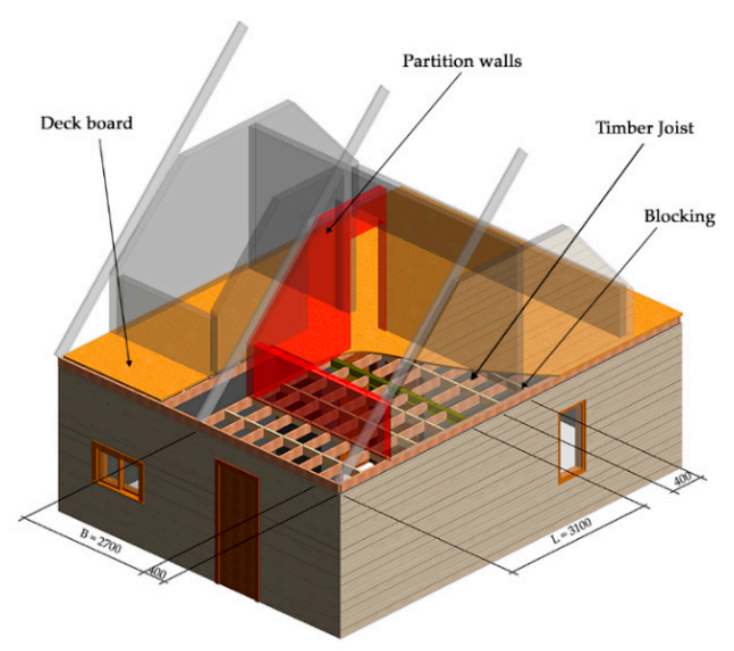

(a)

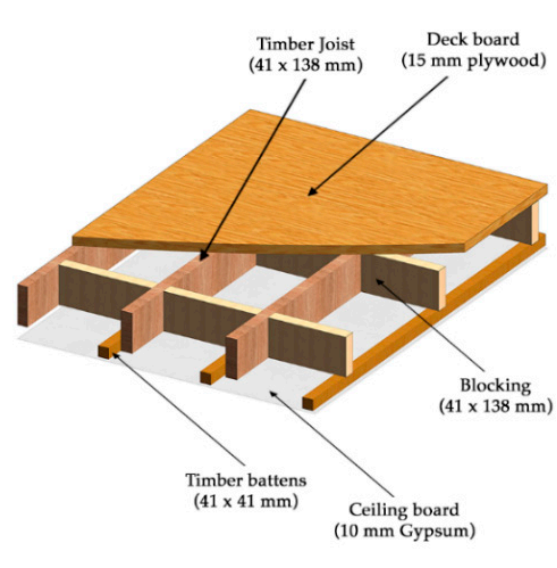

(b)

Figure 6. (a) Layout and dimensions of the Field-3.1-W timber floor; (b) Ceiling-to-joist connections of the Field-3.1-W timber floor. 
Table 3. Nomenclature, dimensions, and support details of in-situ timber floors.

\begin{tabular}{cccc}
\hline Series & Span Length “L” $(\mathrm{m})$ & Floor Width “B” $(\mathbf{m})$ & Support Type \\
\hline Field-2.4-W & 2.4 & 4.4 & Wood-based \\
Field-3.1-W & 3.1 & 2.7 & Wood-based \\
\hline
\end{tabular}

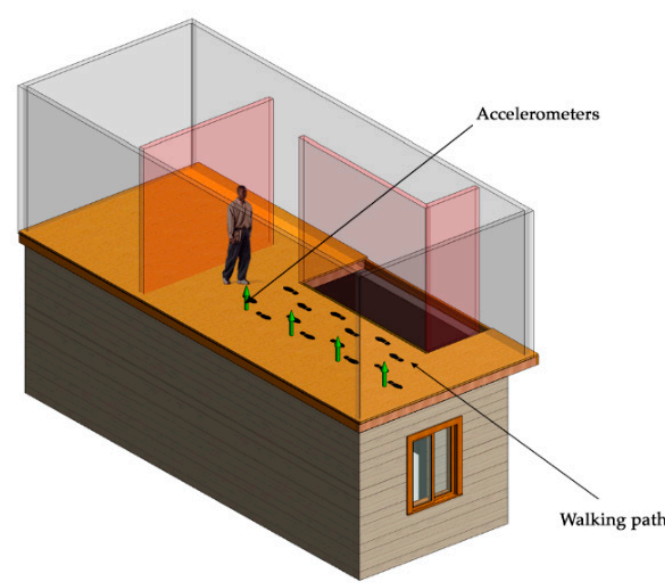

(a)

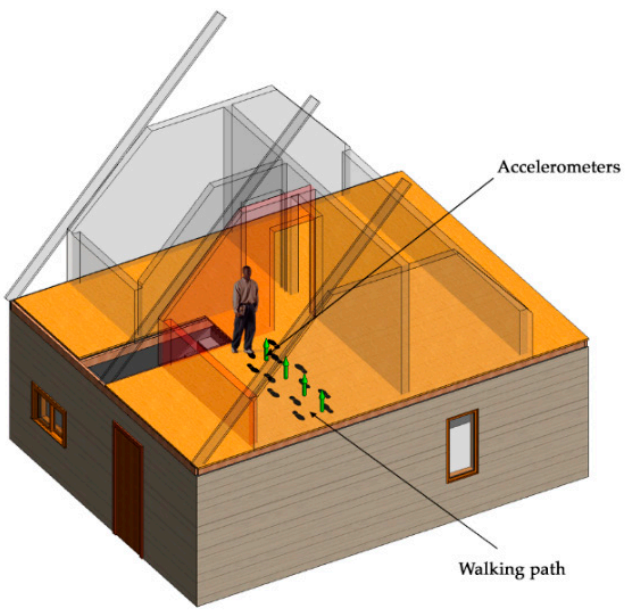

(b)

Figure 7. Walking paths and accelerometer locations on in-situ timber floors: (a) Field-2.4-W timber floor; (b) Field-3.1-W timber floor.

\subsection{Operational Modal Analysis and Damping Ratio Estimations}

Operational Modal Analysis (OMA) is an engineering field that aims to identify the modal properties (modal frequencies, damping, and shapes) of dynamic systems based only on vibration response measurements. OMA provides a series of useful methods that can be classified as parametric and nonparametric. Usually, the parametric methods exhibit a better performance than the nonparametric methods. However, they use procedures that are more complex and computationally demanding. On the other hand, nonparametric methods are faster and easier to use in field tests, since they allow a quick view about the effectiveness of the measurements and the results of dynamic identification [15]. Therefore, it is always convenient to use these two types of methods when trying to identify modal properties as challenging as the damping ratios.

In this study, only the frequency and damping ratio associated with the first resonant mode of the floors was estimated. This decision was based on the results obtained in previous theoretical studies, where a series of timber floors were modeled using the finite element method [16]. For most of the numerical models of the floors, it was found that the first resonant mode had an effective modal mass equivalent to $60 \%$ of the total mass. In contrast, the rest of the modes had effective modal masses less than $10 \%$ of the total floor mass. In this way, it was estimated that the first resonant mode of the floors would have a significant influence on their vibratory performance.

Enhanced Frequency Domain Decomposition (EFDD) $[17,18]$ and Stochastic Subspace Identification (SSI) $[19,20]$ were selected as OMA techniques because they are widely used for modal parameter identification and are based on frequency domain (nonparametric) and time domain (parametric) approaches, respectively. The software package ARTeMIS Modal Pro [21] was used to determine modal frequencies, damping ratios, and shapes of the timber floors under operational-walking conditions for both EFDD and SSI methods.

EFDD is a method based on the singular value decomposition (SVD) of the power spectral density (PSD) matrix and allows the identification of even closely spaced modes. This approach uses four main steps in order to estimate the damping ratio, as is illustrated in Figure 8. 


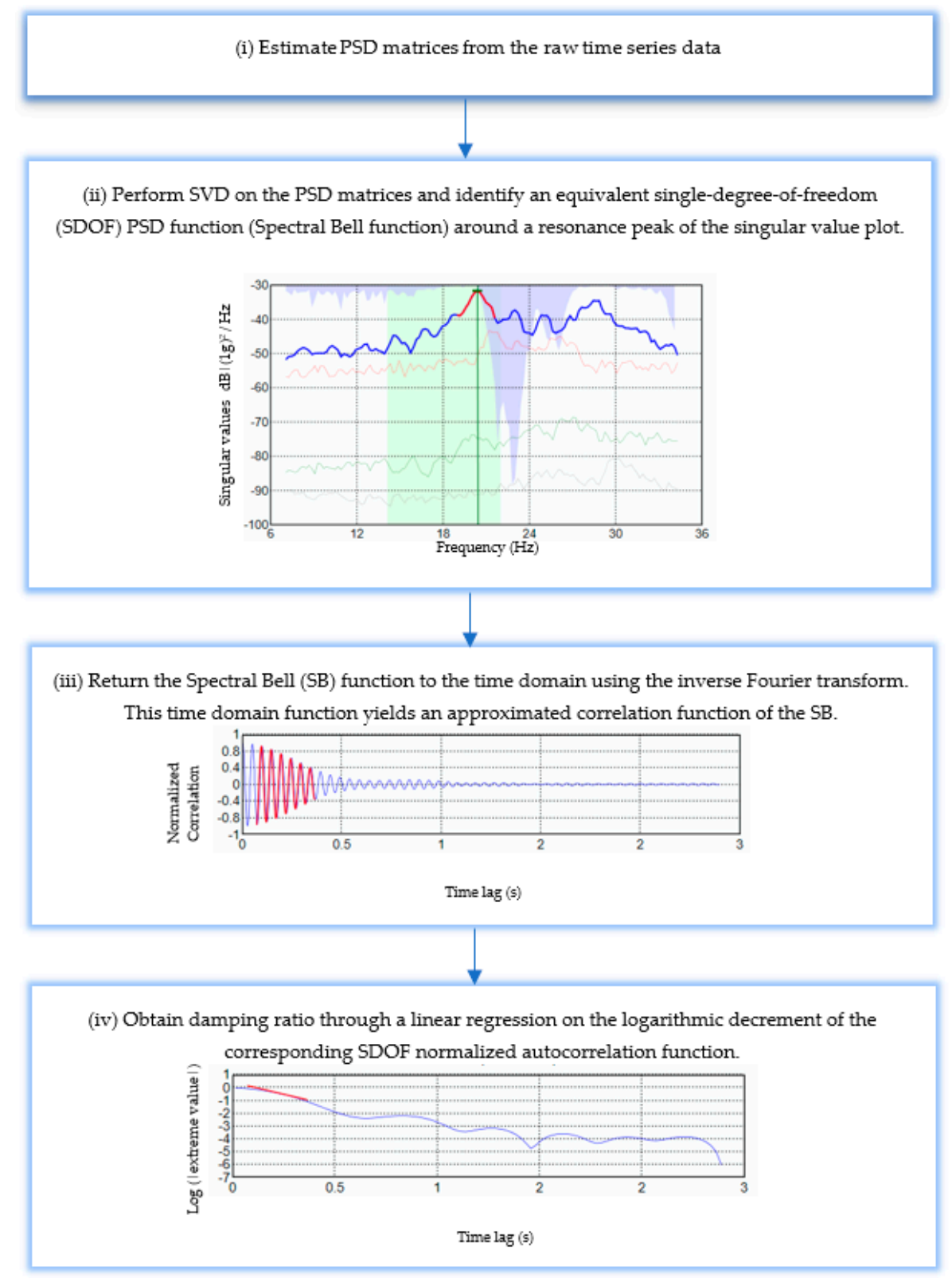

Figure 8. Logical diagram of damping ratio estimation based on the Enhanced Frequency Domain Decomposition (EFDD) method. Extracted from ARTeMIS Modal Pro [21].

Rainieri et al. [22] have suggested some basic test and data processing rules in order to obtain reliable damping ratio estimations with the EFDD method. Firstly, a total record length equal to 1000-2000 times the first natural structural period is usually recommended. This record's lengths are needed to keep the PSD estimation errors low. According to some preliminary numerical simulations, it was estimated that the most flexible tested floors would have fundamental vibration periods of approximately $0.06 \mathrm{~s}$. Therefore, it was decided that consecutive round-trip walks on the floors that had a total duration of at least $72 \mathrm{~s}$ would be conducted. In this way, it was possible to comply with the suggestions of the length records. Secondly, considerable attention must be paid when a frequency resolution is selected. Because the damping estimates improve with the frequency resolution [22], its value was set to $0.101 \mathrm{~Hz}$. This resolution was adequate with respect to the values of resonant frequencies and the modal density found for the timber floors. More details of the EFDD method can be found in [15]. 
On the other hand, SSI is a method in which a parametric model is directly fitted to raw time series data. The purpose of parametric model estimation is to determine a model with a reasonable number of parameters (model order) such that both dynamic and statistical behavior can be correctly represented.

SSI is based on a state-space description of the differential equation of motion, converting the second-order problem into two first-order problems. Therefore, the new problem is defined by the so-called state equation and observation equation. These equations have system matrices (that contain physical and response information) and vectors (related to the statistical information on the input forces). In the context of walking-induced forces, timber floors are excited by non-measurable inputs; consequently, the measured system response is generated by assuming two stochastic white-noise processes related to the model and sensor. According to [14], mobile loads produced by many people randomly walking on a floor at the same time can be classified as multiple-input loads, which are an excellent alternative to meet the assumptions of white noise for excitations. The walking paths shown in Figures $4 \mathrm{a}$ and 7 are not exactly random excitation, but they are suitable for satisfying the white noise excitation assumption in the context of fast in-situ testing. Once the system matrices have been estimated, the modal parameters, such as frequencies, modal shapes, and damping ratios, can be extracted. In general, in the SSI method, it is not possible to determine the model order (dimension " $n$ ") beforehand. Therefore, it is necessary to repeat the analysis with different model orders and verify the repeatability of the results. This procedure is performed by constructing stabilization charts. An SSI data-driven Unweight Principal Component algorithm (SSI-UPC) was selected to extract the damping ratios. This procedure has eight main steps, as is illustrated in Figure 9. More details of the SSI method can be found in [15].
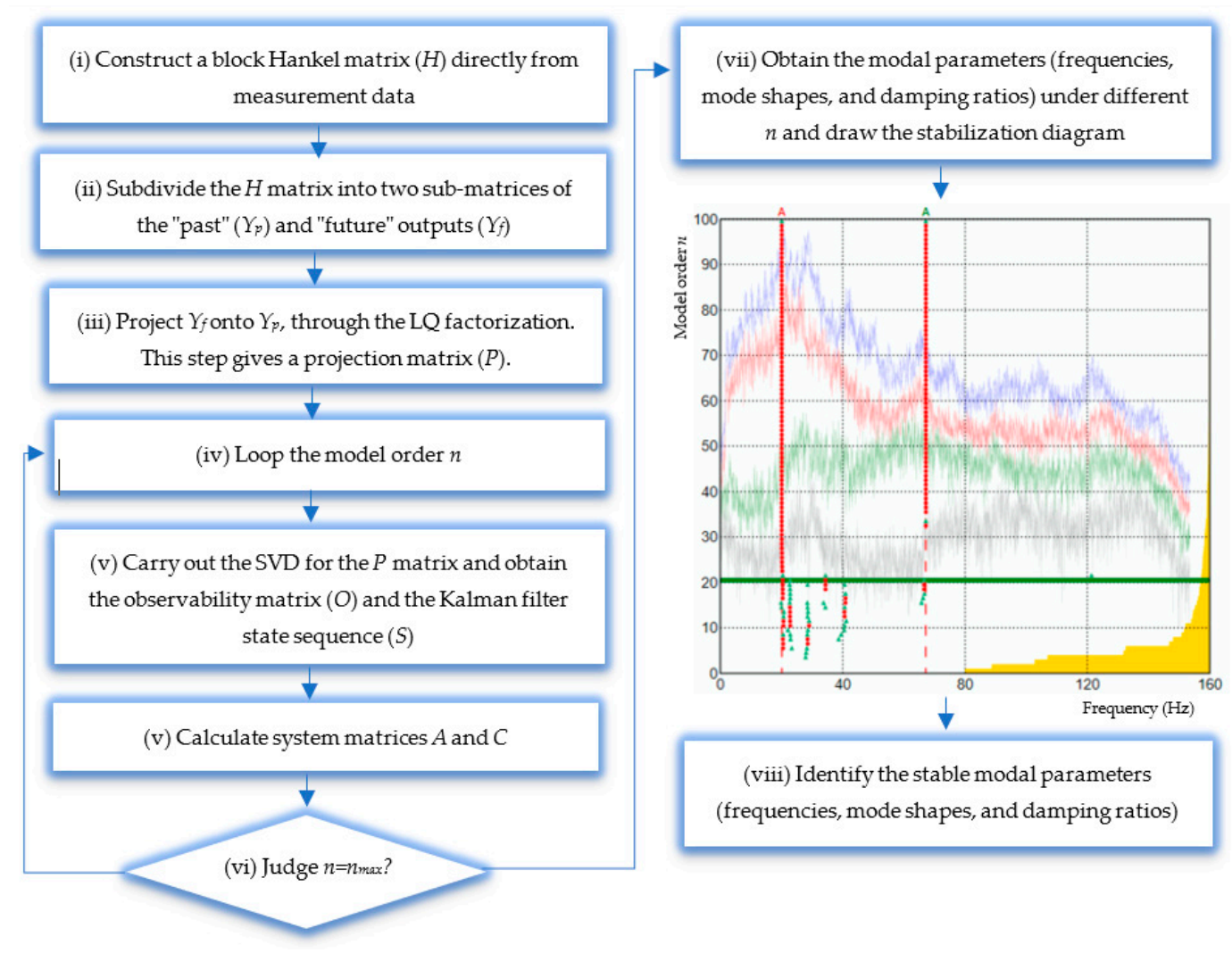

Figure 9. Logical diagram of damping ratio estimation based on the Stochastic Subspace Identification (SSI) method. Extracted from ARTeMIS Modal Pro [21].

\subsection{Floor Vibration Serviceability Parameter}

For evaluating the dynamic vibratory performance of a floor, it is necessary to calculate some reference parameters that can be compared with acceptance criteria established in regulations. In 
order to study the influence of the damping ratios on the floors' dynamic serviceability, the vibration dose value (VDV) was selected. VDV is a time-accumulated vibration parameter that correlates well with the subjective perception of people exposed to vibrations. The physical meaning for this is based on two aspects: (i) VDV uses the fourth power of accelerations because people are sensitive to the maximum acceleration intensity, and (ii) VDV measures accumulated vibrations, instead of averaging it, because people feel more discomfort when they are exposed to long-duration vibrations. For these reasons, the VDV parameter has been recommended by relevant international regulations $[23,24]$ and is currently being used by researchers to evaluate the vibration performance of wooden floors [10]. Its mathematical expression is given by the fourth root of the time integral of the fourth power of the acceleration after it has been frequency weighted $\left(a_{w}\right)$. When the vibration conditions are constant or repeated regularly, only one representative sample, of duration $\tau$ in seconds, needs to be measured (Equation (1)). The acceleration must be weighted, as how people perceive building vibrations depends on various factors, including the vibration frequency and direction. For vertical accelerations, the weighting curve modulus demonstrates the maximum sensibility in the frequency range from $4 \mathrm{~Hz}$ to $12.5 \mathrm{~Hz}$.

$$
V D V_{\tau}=\left\{\int_{0}^{\tau}\left[a_{w}(t)\right]^{4} d t\right\}^{0.25}
$$

On the other hand, it is necessary to extend the effect of an intermittent vibration of a short duration to a daytime of $16 \mathrm{~h}$ [24]. According to [25], in residential buildings, quiet scenarios of people walking are generally expected, so a regular short-duration event of vibration induced by walking should occur every $15 \mathrm{~min}$, that is, 32 times in $16 \mathrm{~h}$. Therefore, the VDV associated with a $16 \mathrm{~h}$ daytime can be expressed as shown in Equation (2):

$$
V D V_{\text {day }}=N^{0.25} \cdot V D V_{\tau}=32^{0.25} \cdot V D V_{\tau}=2.38 \cdot V D V_{\tau}
$$

where $V D V_{\text {day }}$ is the vibration dose value for $16 \mathrm{~h}$ daytime exposure (in $\mathrm{m} \cdot \mathrm{s}^{-1.75}$ ), and $\mathrm{N}$ is the number of times an intermittent vibration of $\mathrm{t}$ seconds of duration occurs in $16 \mathrm{~h}$.

Finally, the $V D V_{d a y}$ obtained from the measurements must be compared with the vibratory performance criteria recommended by [24]. The judgment made is of the probability that the determined vibration dose might result in an adverse comment by those who experienced it (Table 4).

Table 4. Vibration dose value ranges $\left(\mathrm{m} / \mathrm{s}^{1.75}\right)$ which might result in various probabilities of adverse comments within residential buildings.

\begin{tabular}{cccc}
\hline Place and Time & $\begin{array}{c}\text { Low Probability of } \\
\text { Adverse Comment }\end{array}$ & $\begin{array}{c}\text { Medium Probability of } \\
\text { Adverse Comment }\end{array}$ & $\begin{array}{c}\text { High Probability of } \\
\text { Adverse Comment }^{2}\end{array}$ \\
\hline $\begin{array}{c}\text { Residential buildings } \\
\text { 16 h day }\end{array}$ & 0.2 to 0.4 & 0.4 to 0.8 & 0.8 to 1.6 \\
\hline
\end{tabular}

${ }^{1}$ Below these ranges, an adverse comment is not expected. ${ }^{2}$ Above these ranges, an adverse comment is very likely.

\section{Results and Discussion}

\subsection{Dynamic Response of the Timber Floors}

The vibration behavior of all tested floors was a series of transient responses to individual impulses, without any resonance. In each impulse, an initial peak is associated with the first impact of the heel, followed by a free-vibration-like response of the structure, which decays according to the floor damping ratio. Each time another heel strikes the floor, a new transient response is triggered and it decays without generating resonance in the vibration. Some representative examples of the dynamic response of timber floors measured both in the laboratory and in the field are shown in Figure 10. 


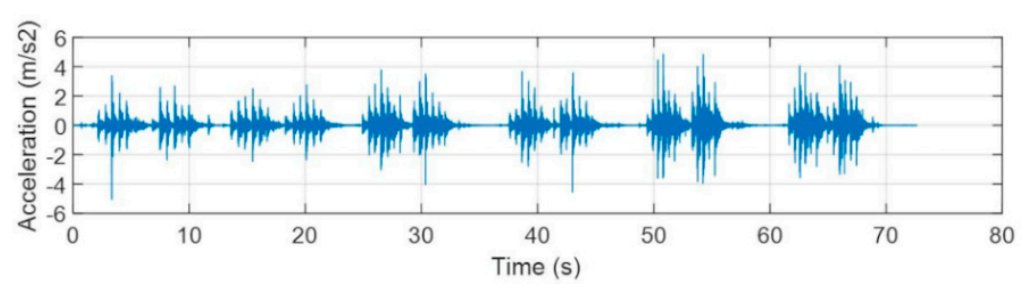

(a)

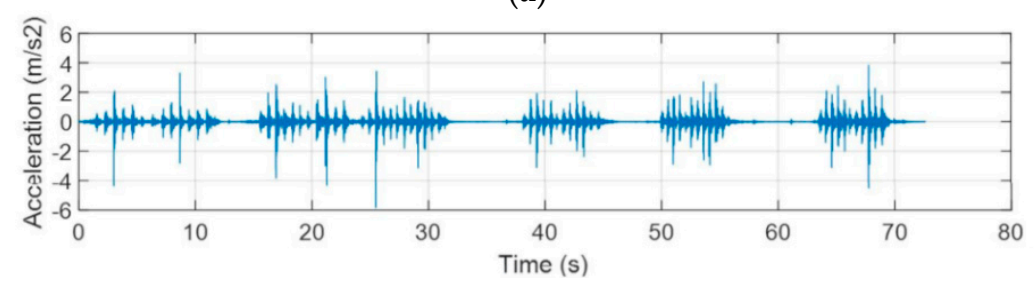

(b)

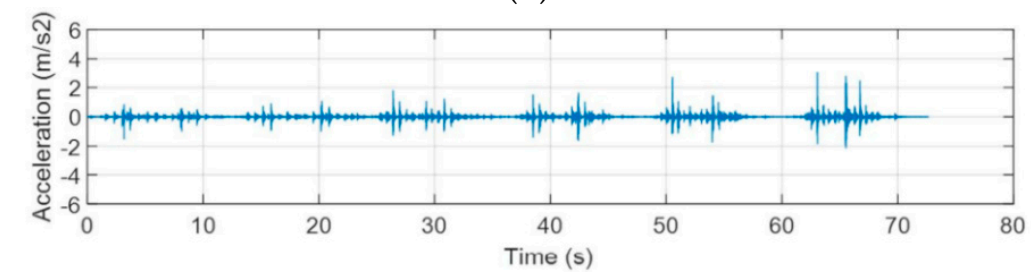

(c)

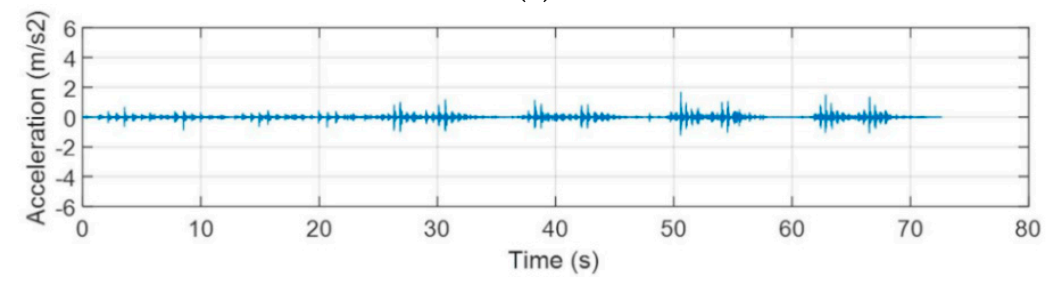

(d)

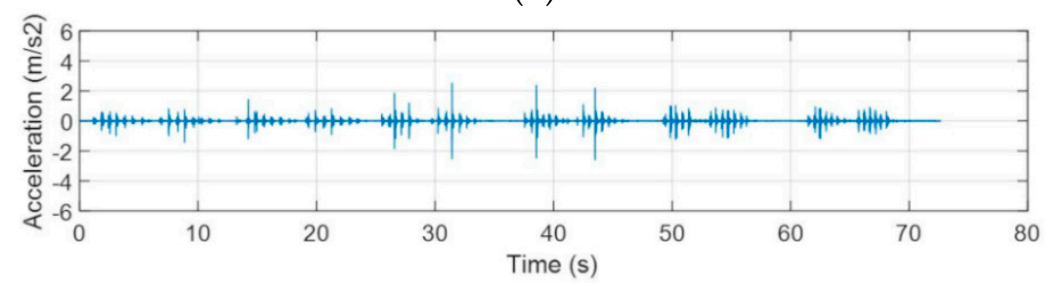

(e)

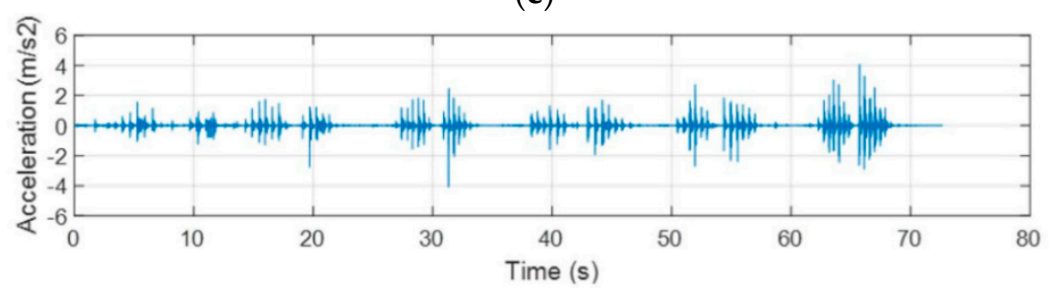

(f)

Figure 10. Typical responses for laboratory and in-situ floors: (a) Lab-3.0-W; (b) Lab-3.0-S; (c) Lab-2.1-W; (d) Lab-21-S; (e) Field-2.4-W; (f) Field-3.1-W.

In Figure 10, specific trends can be observed for both the laboratory floors and in-situ floors. Laboratory floors with larger span lengths (Figure 10a,b) had higher vibration amplitudes than the smaller ones (Figure 10c,d). Similar trends can be observed for the in-situ floors (Figure 10e,f). Meanwhile, for the laboratory floors with the same span length, the ones with wood-based supports had slightly higher vibration amplitudes than the steel-based supported ones (Figure 10a compared with Figure 10b, and Figure 10c compared with Figure 10d). 


\subsection{Fundamental Vertical Vibration Frequencies and Modal Shapes}

Table 5 shows the fundamental vibration frequencies (first resonant frequency) for all floors, obtained through the EFDD and SSI-UPC methods.

Table 5. Fundamental frequencies for laboratory and in-situ timber floors.

\begin{tabular}{|c|c|c|c|c|c|}
\hline \multirow[b]{2}{*}{ Series } & \multicolumn{2}{|c|}{ EFDD } & \multicolumn{2}{|c|}{ SSI-UPC } & \multirow{2}{*}{$\begin{array}{c}\text { Difference (\%) } \\
\text { SSI-EFDD, } \\
\text { EFDD }\end{array}$} \\
\hline & $\begin{array}{c}\text { Mean Value } \\
(\mathrm{Hz})\end{array}$ & $\begin{array}{c}\text { Coef. of } \\
\text { Variation }(\%)\end{array}$ & $\begin{array}{c}\text { Mean Value } \\
(\mathrm{Hz})\end{array}$ & $\begin{array}{c}\text { Coef. of } \\
\text { Variation }(\%)\end{array}$ & \\
\hline Lab-2.1-W & 39.35 & 0.63 & 39.87 & 1.12 & 1.32 \\
\hline Lab-2.1-S & 43.60 & 0.70 & 44.12 & 0.78 & 1.19 \\
\hline Lab-2.4-W & 33.72 & 0.43 & 33.63 & 0.87 & -0.27 \\
\hline Lab-2.4-S & 34.67 & 0.58 & 34.79 & 0.28 & 0.35 \\
\hline Lab-2.7-W & 25.99 & 0.63 & 26.79 & 1.68 & 3.08 \\
\hline Lab-2.7-S & 26.34 & 0.63 & 26.59 & 0.58 & 0.95 \\
\hline Lab-3.0-W & 20.32 & 0.50 & 20.40 & 0.33 & 0.39 \\
\hline Lab-3.0-S & 20.34 & 0.77 & 20.39 & 0.68 & 0.25 \\
\hline Field-2.4-W & 26.45 & 4.59 & 25.70 & 5.79 & -2.84 \\
\hline Field-3.1-W & 16.38 & 4.39 & 16.99 & 4.38 & 3.72 \\
\hline
\end{tabular}

From Table 5, it can be observed that all floors can be classified as high frequency according to [24], since their fundamental vibration frequencies were always greater than $10 \mathrm{~Hz}$. Concerning modal identification methods, both EFDD and SSI-UPC were able to determine very similar fundamental frequencies. The percentage differences between the methods did not exceed $4 \%$. In addition, the frequency measurements were stable, since the coefficients of variation did not exceed $6 \%$. These low values of the coefficients of variation also suggest that the floors had a predominantly linear elastic behavior. If the nonlinearity had been high, the vibration frequencies would have a more significant dispersion for the 36 person walks executed. Therefore, if there was incursion in the non-linear range, it was very slight, and mainly related to the activation of minor friction mechanisms between timber joints. From the above, it follows that the assumption of the floor's linear behavior is still reasonably valid.

Similarly, it can be observed that for laboratory floors, as the span length decreases, the vertical frequency and, therefore their stiffness, increases. Besides, the floors that had steel-based supports achieved higher frequencies than those that were wood-based supported. This effect was more evident in the floors of shorter span lengths, and disappeared as the span lengths increased.

For the in-situ floors, the effect of the presence of a ceiling and partition walls in the vibration frequency could be observed. Both the Field-2.4-W and Field-3.1-W floors had fundamental frequencies that were $20 \%$ lower than the laboratory floors with similar lengths. Therefore, it was observed that both the ceiling and partition walls increased the floors' mass, but not their vertical stiffness.

In order to confirm that the vibration frequencies found with the EFDD and SSI-UPC methods correspond to the fundamental vibrational mode of the floors, it was necessary to graph their modal shapes. Figures 11 and 12 show some examples of the fundamental vibration modes found for both laboratory and in-situ floors. 

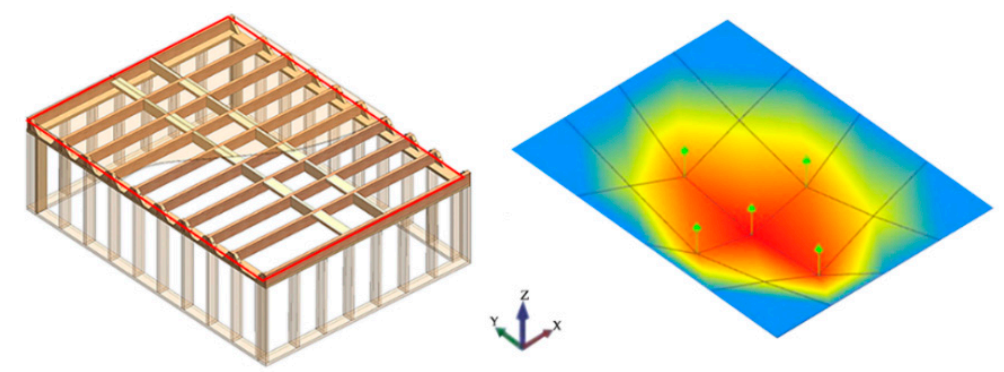

Figure 11. Measured fundamental vibration mode for the Lab-3.1-W floor (20.32 Hz Enhanced Frequency Domain Decomposition (EFDD) method). Extracted form ARTeMIS Modal Pro [21].
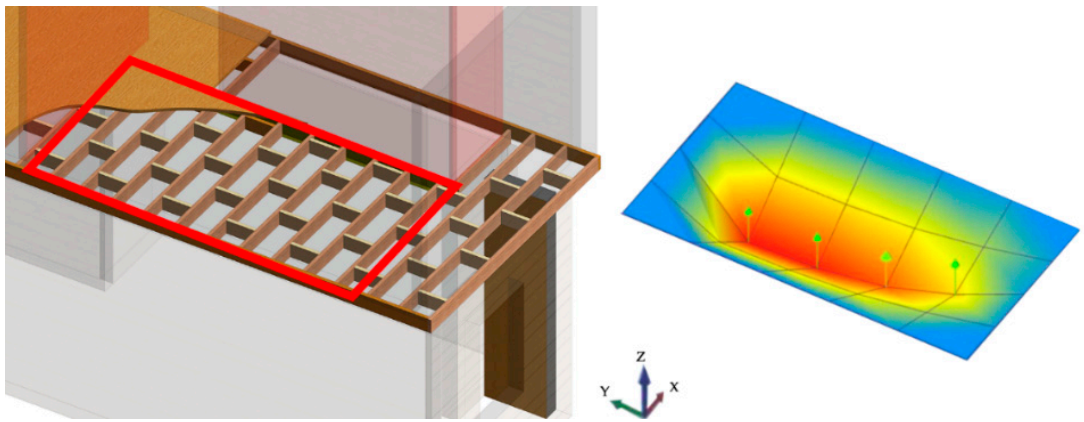

(a)
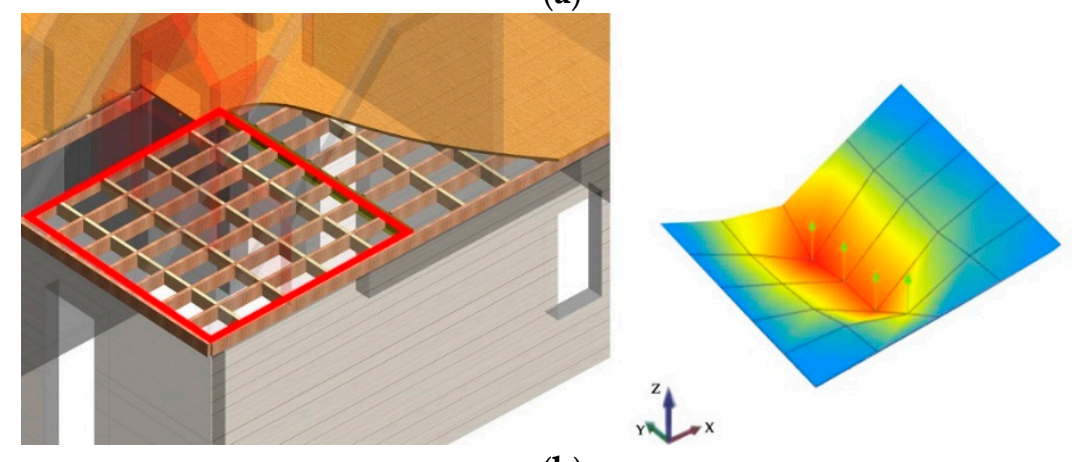

(b)

Figure 12. Measured fundamental vibration mode for: (a) Lab-2.4-W floor (26.45 Hz Enhanced Frequency Domain Decomposition (EFDD) method); (b) Field-3.1-W (16.38 Hz EFDD method). Extracted form ARTeMIS Modal Pro [21].

From Figures 11 and 12, it can be deduced that the detected vibration modes corresponded to the fundamental vibration modes in the vertical direction. When these modes of vibration are excited by people walking, they can generate relevant levels of vertical accelerations in the floors and, therefore, user discomfort.

\subsection{Fundamental Damping Ratios}

Figure 13 shows a boxplot with the damping ratios of all the floors evaluated with the EFDD and SSI-UPC methods. 


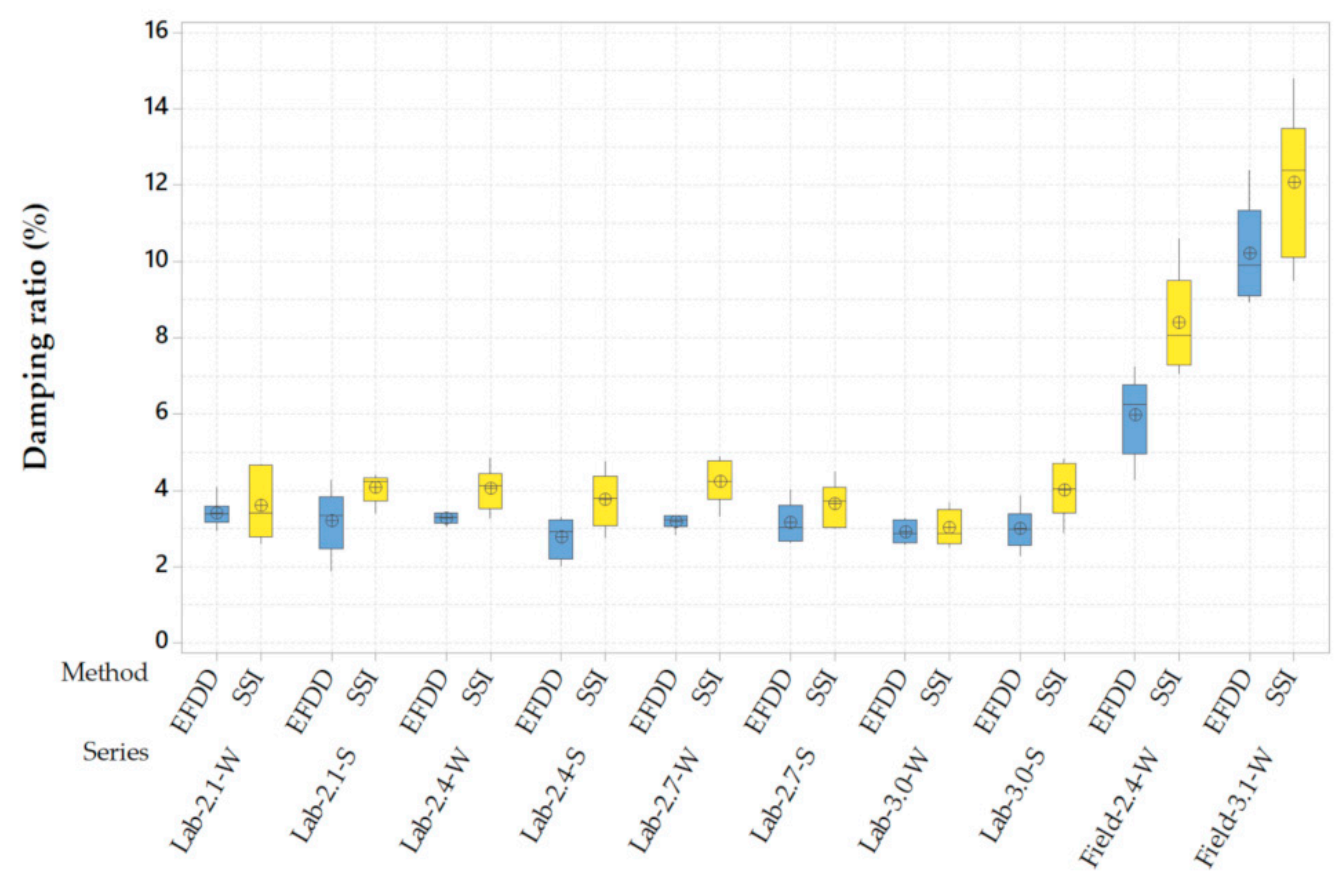

Figure 13. Boxplot of fundamental damping ratios.

It can be seen from Figure 13 that there is a clear difference between the damping ratios of the laboratory floors and the in-situ floors. While the laboratory floors had damping ratios between $1.9 \%$ and $4.9 \%$, the field floors reached values between $4.3 \%$ and $14.8 \%$. Additionally, the SSI-UPC method presented average damping ratios that were 1.24 times greater than those of the EFDD method. Concerning the coefficients of variation of the damping ratios, it is observed that they are much higher than those obtained in the frequencies (Table 5); however, they remain at reasonable values (less than $25 \%$ ) given the difficulty of estimating this dynamic property experimentally.

To determine whether the differences in the damping ratios of the different laboratory floors were statistically significant, an analysis of variance (ANOVA) was applied. Using a level of significance of 0.05 for the results of the EFDD method, the ANOVA indicated that the differences between the means of laboratory and in-situ tests were not statistically significant $(p=0.199>0.05)$. However, when applying the ANOVA to the damping ratios with the SSI-UPC method, statistically significant differences were obtained between the means of laboratory and in-situ tests $(p=0.028<0.05)$. In particular, the SSI-UPC method detected that the Lab-3.0-W floor was significantly lower than the Lab-2.7-W and Lab-2.1-S floors. The above described situation could imply that for floors with distances close to $3 \mathrm{~m}$, it would not be advisable to use wood-based supports, since ranges of damping ratios could be smaller than the general trend of the rest of the cases. Besides, these results demonstrate the importance of evaluating the damping ratios with different methods, as they complement each other and make it possible to detect trends that might not be observed with a single method. Table 6 shows the confidence intervals of the means (95\%) obtained by the ANOVA for the laboratory floors. 
Table 6. Confidence intervals (95\%) for the fundamental damping ratios (\%) of laboratory floors.

\begin{tabular}{ccc}
\hline Series & EFDD & SSI-UPC \\
\hline Lab-2.1-W & $(3.01 ; 3.80)$ & $(2.65 ; 4.53)$ \\
Lab-2.1-S & $(2.32 ; 4.07)$ & $(3.67 ; 4.46)$ \\
Lab-2.4-W & $(3.11 ; 3.43)$ & $(3.47 ; 4.62)$ \\
Lab-2.4-S & $(2.22 ; 3.31)$ & $(2.99 ; 4.52)$ \\
Lab-2.7-W & $(2.98 ; 3.38)$ & $(3.62 ; 4.82)$ \\
Lab-2.7-S & $(2.55 ; 3.72)$ & $(3.05 ; 4.25)$ \\
Lab-3.0-W & $(2.60 ; 3.22)$ & $(2.52 ; 3.49)$ \\
Lab-3.0-S & $(2.44 ; 3.56)$ & $(3.25 ; 4.77)$ \\
\hline
\end{tabular}

Other interesting results worth analyzing are the high levels of damping ratios that were found in the in-situ floors. On the Field-2.4-W floor, damping ratios were found to be twice as high as those of the laboratory floors. This increase is attributed to the interaction of the floors with some non-structural elements (for example, ceilings and partition walls), together with the higher level of restriction to the rotation of the floor supports due to the weight of the perimeter walls (Figure 5). All of these interactions more strongly activated some energy dissipation by friction mechanisms and therefore increased the values of the damping ratios. On the other hand, for the Field-3.1-W floor, the effect of the interaction with the non-structural elements was even more evident. The Field-3.1-W floor resembles the Field-2.4-W floor in that it also has a ceiling and partition walls in the perimeter of the floor. However, the more significant constructive difference is that the Field-3.1-W floor also has a partition wall that crosses all the timber joists in the third of its length. Besides, this partition wall directly supports a part of the roof structure of the house (Figure 6). Because of the presence of this unusual partition wall, the floor of the Field-3.1-W housing presents damping ratios three times greater than those of laboratory floors.

The damping ratios found both for the laboratory floors and the in-situ floors are higher than those indicated by other researchers. As stated before, the ranges of damping ratios reported by other studies were between $0.52 \%$ and $4.78 \%$ for laboratory floors [3-8] and between $0.47 \%$ and $9.10 \%$ for in-situ floors [9-12]. These values contrast to some extent with the ranges reported in the present study, which were between $1.9 \%$ and $4.9 \%$ for laboratory floors and from $4.3 \%$ to $14.8 \%$ for in-situ floors. However, these differences are logical and could be explained by the fact that the vibrations induced by people walking have a higher amplitude than the ambient-, impact-, or shaker-induced vibrations used by the rest of the investigations. Therefore, it is likely that vibrations of a higher amplitude activate more energy dissipation mechanisms between the components of the floors and consequently increase their damping ratios.

Another essential aspect to consider that explains the increase in damping is the human-structure interaction (HSI). In this context, HSI could be explained as the continuous reciprocal dynamic vertical effects of a human and floor on each other, which acts in a feedback loop, as long as the floor and human on it are in contact [26]. One of the HSI categories involves the effects of the human body, considered as a mass-spring-damper system (dynamic system), on the dynamic properties of the floor (mass, stiffness, and damping). In the case of human walking, a set of floor reaction forces are generated due to the self-propelling body motion [27]. These interaction forces have components proportional to acceleration, velocity, and displacement, as well as autonomous components. Therefore, they could be evidenced as shifts in the modal frequency and damping of the empty floor. As reported by [27], when two people walked together across a post-tensioned concrete footbridge, the damping ratio associated with the first resonant mode increased 1.5 times in relation to the empty footbridge. On timber floors, it is also expected that this physical phenomenon occurs; however, new numerical-experimental investigations should be developed to quantify this effect adequately. 


\subsection{Vibration Dose Values for Timber Floors}

As stated previously, the $V D V_{\text {day }}$ indicator was selected to evaluate the vibratory performance of the floors and analyze the influence of the damping ratio on them. Figure 14 shows the results of $V D V_{\text {day }}$ for the laboratory and in-situ floors, along with the normative limits that define the different probabilities of adverse comments by users.

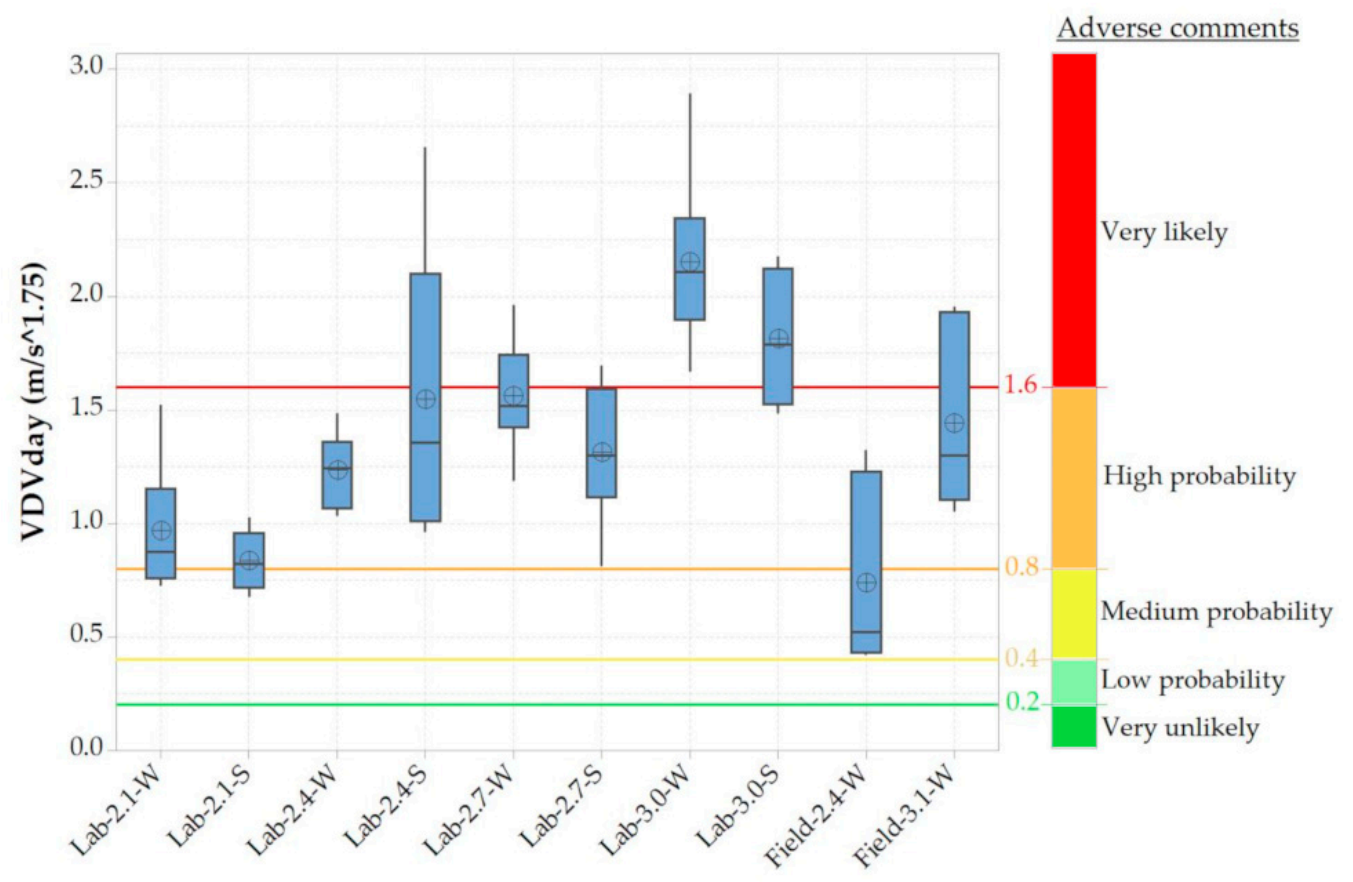

Figure 14. Boxplot of vibration dose value $(V D V)_{\text {day }}$ for timber floors.

From Figure 14, it can be observed that no floor had a vibratory performance in which adverse comments are not expected $\left(V D V_{\text {day }}<0.2\right)$. On the other hand, two laboratory floors (Lab-3.0-W and Lab-3.0-S) had average values of $V D V_{d a y}$ in the area with the worst vibratory performance, where adverse comments are very likely $\left(V D V_{d a y}>1.6\right)$. The majority of the floors (six laboratory floors \{Lab-2.1-W, Lab-2.1-S, Lab-2.4-W, Lab-2.7-W, Lab-2.7-S $\}$ and one in-situ floor \{Field-3.1-W\}) remained in the area where adverse comments have a high probability of occurrence $\left(0.8<V D V_{\text {day }}<1.6\right)$. Finally, the floor with the best vibratory performance (Field-2.4-W) stayed in the area where adverse comments have a medium probability of occurrence $\left(0.4<V D V_{\text {day }}<0.8\right)$.

In order to study the influence of the damping ratio on the vibration performance, floors that have similar resonant frequencies should be compared. For example, in Table 5, it can be seen that floors Lab-2.7-W, Lab-2.7-S, and Field-2.4-W had frequencies that were very similar and close to $26 \mathrm{~Hz}$. However, the mean value of the damping ratio of the Field-2.4-W floor was 2.1 times higher than the Lab-2.7-W and Lab-2.7-S floors (Table 6), which caused the $V D V_{\text {day }}$ indicators to be reduced by $48 \%$ and achieve the best vibratory performance of all of the evaluated floors.

Other evidence of the positive influence of the damping ratio on the vibration performance of the floors was observed for the Field-3.1-W floor. This floor had the most extended span length $(3.1 \mathrm{~m})$ and the lowest resonant frequency (approximately $16 \mathrm{~Hz}$ ), so it was expected to have the worst vibratory performance. However, because this floor had the highest damping ratios (between $9 \%$ and $15 \%$ ), its vibration performance was better than expected, being comparable to floors that had smaller span lengths and higher frequencies (Lab-2.4-S). 


\section{Conclusions}

This paper has highlighted the importance of the damping ratio in the dynamic serviceability of lightweight timber floors that are typical in social housing projects, under human-walking excitations. The experimental campaign revealed ranges of values for damping ratios for both floors built in the laboratory and existing homes. The different dimensions and constructive details of the floors, together with the two operational modal analysis methods used for estimating the damping ratios, have allowed the current knowledge about this research topic to be extended.

For the floors constructed in the laboratory, damping ratios were obtained in the range of $1.9 \%$ to $4.9 \%$. In general, there were few statistically significant differences between the laboratory floors with different span lengths and types of support. Only the $3 \mathrm{~m}$ long floor with wood-based supports (Lab-3.1-W) had significantly lower values of damping ratios and a worse vibration performance, so its use in social housing projects is not recommended.

For the floors evaluated in-situ, damping ratios were obtained in the range of $4.3 \%$ to $14.8 \%$, presenting values between 2 and 3 times greater than those of the laboratory floors. The reason for these increases in damping was mainly due to the presence of non-structural elements, such as a ceiling and partition walls. This favorable effect of the non-structural elements in the damping ratio confirms what was indicated by other researchers.

Concerning the methods used to calculate the damping ratio from experimental tests, the importance of using at least one that works in the frequency domain and another in the time domain is confirmed. On average, the SSI-UPC method obtained damping values that were 1.24 times higher than those of the EFDD method. Besides, the combined use of both methods provides further reliability to the results and detects tendencies that are challenging to find with a single method.

Damping ratios higher than those indicated in other studies were obtained for both the floors built in the laboratory and those evaluated in-situ. These results show that the amplitudes of vibrations induced by walking are larger and activate more energy dissipation mechanisms in the floors than the ambient vibration or low-energy impact tests used by other researchers. However, these increases in the damping ratios were not only due to the activation of new energy dissipation mechanisms, but also due to the human-structure interaction that occurred during the walks. Therefore, it is desirable to carry out new numerical investigations to quantify the contributions of the different physical phenomena to the total damping of the timber floors.

Finally, the positive influence of the damping ratio on the vibration performance of the floors was identified. For floors with similar vibration frequencies, it was observed that those with 2.1 times larger damping ratios had $V D V_{d a y}$ values that were up to $48 \%$ lower. These results allowed some floors to move from unacceptable vibration levels for users to others where it is possible that users generate adverse comments, but within a tolerable range of vibrations.

Author Contributions: Conceptualization, A.O.-V. and C.O.-V.; methodology, A.O.-V. and C.O.-V.; software, A.O.-V. and F.M.-V.; validation, C.O.-V. and A.O.-V.; formal analysis, A.O.-V.; investigation, A.O.-V. and F.M.-V.; data curation, A.O.-V. and F.M.-V.; writing—original draft preparation, A.O.-V.; writing—review and editing, C.O.-V.; visualization, A.O.-V. and F.M.-V.; supervision, C.O.-V.; project administration, A.O.-V.; funding acquisition, A.O.-V.

Funding: This research was funded by the UNIVERSITY OF BIO-BIO RESEARCH DIRECTORATE, grant number DIUBB 151714 2/R.

Acknowledgments: The authors gratefully thank the support of the Civil Engineering Doctoral Program at Universidad Católica de la Santísima Concepcion (UCSC).

Conflicts of Interest: The authors declare no conflict of interest.

\section{References}

1. Hu, L.J.; Chui, Y.H.; Onysko, D.M. Vibration serviceability of timber floors in residential construction. Prog. Struct. Eng. Mater. 2001, 3, 228-237. [CrossRef] 
2. Weckendorf, J.; Toratti, T.; Smith, I.; Tannert, T. Vibration serviceability performance of timber floors. Eur. J. Wood Prod. 2016, 74, 353-367. [CrossRef]

3. Labonnote, N.; Rønnquist, A.; Malo, K.A. Prediction of material damping in timber floors, and subsequent evaluation of structural damping. Mater. Struct. 2015, 48, 1965-1975. [CrossRef]

4. Bernard, E.S. Dynamic Serviceability in Lightweight Engineered Timber Floors. J. Struct. Eng. 2008, 134, 258-268. [CrossRef]

5. Zhang, B.; Kermani, A.; Fillingham, T. Vibrational performance of timber floors constructed with metal web joists. Eng. Struct. 2013, 56, 1321-1334. [CrossRef]

6. Zhang, B.; Kermani, A.; Fillingham, T. Vibrations of metal web joist timber floors with strongbacks. Proc. Inst. Civ. Eng. Struct. Build. 2015, 169, 549-562. [CrossRef]

7. Rijal, R.; Samali, B.; Shrestha, R.; Crews, K. Experimental and analytical study on dynamic performance of timber floor modules (timber beams). Constr. Build. Mater. 2016, 122, 391-399. [CrossRef]

8. Quang Mai, K.; Park, A.; Nguyen, K.T.; Lee, K. Full-scale static and dynamic experiments of hybrid CLT-concrete composite floor. Constr. Build. Mater. 2018, 170, 55-65. [CrossRef]

9. Jarnerö, K.; Brandt, A.; Olsson, A. Vibration properties of a timber floor assessed in laboratory and during construction. Eng. Struct. 2015, 82, 44-54. [CrossRef]

10. Casagrande, D.; Giongo, I.; Pederzolli, F.; Franciosi, A.; Piazza, M. Analytical, numerical and experimental assessment of vibration performance in timber floors. Eng. Struct. 2018, 168, 748-758. [CrossRef]

11. Homb, A.; Kolstad, S.T. Evaluation of floor vibration properties using measurements and calculations. Eng. Struct. 2018, 175, 168-176. [CrossRef]

12. Xiong, H.; Kang, J.; Lu, X. Field Testing and Investigation of the Dynamic Performance and Comfort of Timber Floors. J. Asian Archit. Build. Eng. 2011, 10, 407-412. [CrossRef]

13. NCh1198:2014. Madera-Construcciones en madera-Cálculo. Instituto Nacional de Normalización Chile. 2014. Available online: http://normastecnicas.minvu.cl/ (accessed on 17 June 2019).

14. Brincker, R.; Ventura, C. Introduction to Operational Modal Analysis, 1st ed.; John Wiley \& Sons: Hoboken, NJ, USA, 2015; pp. 149-199.

15. Rainieri, C.; Fabbrocino, G. Operational Modal Analysis of Civil Engineering Structures, 1st ed.; Springer: New York, NY, USA, 2014; pp. 103-210.

16. Peña, J. Numerical Evaluation of the Vibrational Performance of Timber Floors. Bachelor's Thesis, University of Bío-Bío, Concepcion, Chile, 2016. Available online: http://ubb.cl/435685 (accessed on 19 August 2019). (In Spanish).

17. Brincker, R.; Zhang, L.; Andersen, P. Modal identification from ambient responses using frequency domain decomposition. In Proceedings of the 18th International Modal Analysis Conference (IMAC), San Antonio, TX, USA, 1 January 2000.

18. Gade, S.; Møller, N.B.; Herlufsen, H.; Konstantin-Hansen, H. Frequency domain techniques for operational modal analysis. In Proceedings of the 1st International Operational Modal Analysis Conference (IOMAC), Copenhagen, Denmark, 26-27 April 2005.

19. Van Overschee, P.; De Moor, B.L. Subspace Identification for Linear Systems: Theory—Implementation—Applications, 1st ed.; Kluwer Academic Publishers: Dordrecht, The Netherlands, 1996; pp. 55-91.

20. Peeters, B. System Identification and Damage Detection in Civil Engineering. Ph.D. Thesis, Katholieke University Leuven, Leuven, Belgium, 2000.

21. ARTeMIS Modal Pro, Version 5.3, Structural Vibration Solutions A/S, Aalborg Denmark, Copyright 1999-2013. Available online: http://www.svibs.com/index (accessed on 17 June 2019).

22. Rainieri, C.; Fabbrocino, G.; Cosenza, E. Some remarks on experimental estimation of damping for seismic design of civil constructions. Shock Vib. 2010, 17, 383-395. [CrossRef]

23. ISO 10137:2007(en) Bases for Design of Structures-Serviceability of Buildings and Walkways against Vibrations. 2007. Available online: https://www.iso.org/obp/ui/\#iso:std:iso:10137:ed-2:v1:en (accessed on 17 June 2019).

24. BS 6472-1:2008. Guide to Evaluation of Human Exposure to Vibration in Buildings. Vibration Sources Other than Blasting. 2008. Available online: https://shop.bsigroup.com/ProductDetail/?pid=000000000019971044 (accessed on 17 June 2019).

25. Ellis, B.R. Serviceability evaluation of floor vibration induced by walking loads. Struct. Eng. 2001, 79, 30-36. 
26. Shahabpoor, E.; Pavic, A.; Racic, V. Interaction between walking humans and structures in vertical direction: A literature review. Shock Vib. 2016, 2016, 22. [CrossRef]

27. Shahabpoor, E.; Pavic, A.; Racic, V. Identification of mass-spring-damper model of walking humans. Structures 2016, 5, 233-246. [CrossRef] 